\title{
IN-VITRO SENSITIVITY PATTERNS OF OCULAR MICROBIAL ISOLATES TO HUMAN URINE THERAPY
}

\author{
BY \\ *OSITA-EMINA, N. M. AND UDUOISE, I. B. \\ DEPARTMENT OF OPTOMETRY, \\ UNIVERSITY OF BENIN, \\ BENIN-CITY, NIGERIA. \\ *Corresponding author
}

\begin{abstract}
The in-vitro sensitivity test carried out with urine as an antimicrobial agent showed that it fell short of the expectation. The maximum margin over WHO standard of $0.7 \mathrm{~cm}$ inhibition zone was $0.2 \mathrm{~cm}$, and the minimum was zero. The mean value for urine zone of inhibition was $0.63 \mathrm{~cm}, \mathrm{SD} \pm 0.018,0.07 \mathrm{~cm}$ below the expected standard for chemotherapeutic use. In spite of these, the use of urine therapy for ocular diseases is socially unacceptable. Fifty (50) samples of urine were obtained for the study, but only 3 were free from various abnormalities. Therefore, the use of urine for treatment of ocular diseases should be discouraged and condemned.
\end{abstract}

KEYWORDS: Urine, Zone of inhibition, Ocular disease,

\section{INTRODUCTION}

The human eye is susceptible to bacterial, viral, fungal and parasitic infections, especially where the condition is most favourable for their growth; thus, conjunctivitis, keratitis, trachoma and blepharitis to mention a few are common eye diseases in the tropics ${ }^{1}$. Therefore an infected eye has various form of microorganisms ${ }^{2}$.

An isolated microorganism from the eye may be pathogenic or a part of the normal flora of the eye, therefore, identification of the disease causing organism in the eye is necessary for effective tratment ${ }^{3}$. This is the adopted procedure of orthodox medicine to cure an infected or diseased eye.

Long before the advent of science our forefathers successfully treated ailments with local herbs. This is considered as alternative therapy by Lewith et $\mathrm{al}^{4}$ Alternative therapies include Naturopathy, Acupuncture, Herbal medicine, Mind-body medicine, Nutritional medicine and Homeopathy. Fulder ${ }^{5}$ sued for a useful working definition for alternative therapy; based on the fact that they were separated and odd to conventional medical principles.

Nevertheless, since 1990 attempts have been made to blend medical and non-orthodox medicine together, for this reason the words natural medicine and holistic medicine have been used loosely as an umbrella ${ }^{6}$. Despite all the short falls to merge these practices, some people continued to patronize alternative medicine practitioners, partly because of the bias against artificial medicine and partly as a result of conventional doctor inability to heal them $^{7}$. In McGuire ${ }^{8}$ report, it was shown that both users and non-users of non-orthodox medicine were critical of the passive attitude orthodox doctors seem to pre-suppose on the part of the patient, who they really did not care for.

It is obvious that alternative medicine practitioners now use urine for various ailments, but the concern is in the efficacy of urine to eye diseases. Heaven ${ }^{9}$ a naturopathist, argued that urine was medicinal, cleansing and nourishing food with a surprising ability to cure varieties of illness. He added that urine was antibacterial, antifungal and antiviral. Newberry ${ }^{10}$ added his voice to the campaign on alternative use of urine as a cure to ñpink eyeò. For this cause, this study is designed to investigate the efficacy of urine therapy in the treatment of eye diseases by an in-vitro approach. The efficacy of the antibiotic on microbial isolates as opposed to urine therapy will be considered in another journal.

\section{MATERIALS AND METHOD}

Eye swabs were collected from fifty subjects of different ages and sexes at University of Benin Teaching Hospital eye clinic. The eye swab for each patient was identified by number. Individual eye swab was inoculated immediately on an already prepared agar plate containing different nutrient media and incubated at $37^{\circ} \mathrm{C}$ for 18 to 24 hours, from which pure culture plates of all isolate were prepared for sensitivity disc diffusion method. The antibacterial agents employed in the 
study where Chloramphenical (0.5\%), Gentamicin $(0.3 \%)$ and Tobranycin $(0.3 \%)$. These antibiotics were employed in the sensitivity tests of ocular microbial isolates, using disc diffusion method.

All the pure isolates were identified by standard techniques described by Cowan and Steel ${ }^{11}$, by their morphology, cultural characteristics, biochemical reaction and fermentation test. A smear of the culture was put on a clear grease-free slide and dried, by passing the slide over a gentle Bunsen burner flame. It was then flooded with the crystal violet rinsed with water. The slide was later stained with Ingols' iodine, decolorized using acetone, immediately again rinsed in water and allowed to dry. The prepared specimen was later viewed under the microscope with X10.0D magnification. Sugar reaction test was performed using glucose, sucrose, manitol, lactose and maltose for the procedure. A colour change from green to yellow was positive $(+\mathrm{ve})$; when $5 \mathrm{ml}$ of peptone water containing each organism, the had were previously incubated at $37^{\circ} \mathrm{c}$ for 4 to 6 hours and inoculated into the sugar solution, was tested with Bromocresol green indicator and Durham tube inverted in the bottle and incubated at $37^{\circ} \mathrm{C}$ for 3 to 5 hours. If there was any displacement of the solution in the Durham tube, it indicated gas production. If there was no color change, the result was negative (ve).

Catalase test was performed; the production of gas bubbles from the surface of the solid culture material showed a positives (+ve) reaction, while no production of gas was indicated as negative (ve).

Catalase test was performed; the production of gas bubbles from the surface of the solid culture material showed a positives (+ve) reaction, while no production of gas was indicated as negative $(+\mathrm{ve})$.

Oxidase test: This test depends on the presence of certain oxidase in the bacteria that will catalyze the transport of electron between the bacteria and the redox dye. A positive reaction reduces the dye to deep purple colour.

Coagulase test: Coagulase is a simple enzyme like product of staphylococcus aureus which causes coarse clumps visible to the naked eye to be formed when and adhering plasma trace was stirred into the drop of the bacterial suspension on the slid. The clumps indicate a positive test (+ve).

Motility test: This is when peptone water is put on a drop of the culture sample surrounded by plasticin and slide covered with cover slip and viewed under the microscope using X40 objectives. Motile organism may be seen in streams or somersaulting.

Urea test: This is used for organisms that hydrolyse urea by changing its colour to pink with the aid of an enzyme called urease.

Indole test: This is based on the ability of the bacteria to break down indole to tryptophane, with the help of an enzyme tryptophanase; and on adding Kovac reagent a pinkish colouration is produced at the interface which indicates indole production.

Citrate test: Some organizations utilize citrate as source of carbon for energy. Turbidity of the peptone water may be formed when the bacteria utilize the citrate; this indicates a positive (+ve) test.

\section{COLLECTION AND PREPARATION OF URINE SAMPLE}

The first void morning urine of each individual was collected with numbered (for identification) sterile test tube. Urine analysis was carried out on the collected samples to rule out the presence of bacteria, liver malfunction and diabetes mellitus. The disc diffusion method was then used in determining the sensitivity pattern of ocular microbial isolates to human urine. Three urine samples out of 50 were found fit and free from disease conditions.

\section{SENSITIVITYTEST}

The sensitivity patterns of the ocular microbial isolates to human urine and topical antibiotic eye drops were determined using disc diffusion method. Two Multo disc were soaked separately with urine and antibiotic, and placed respectively on the aseptic surfaces of two labeled nutrient agar plates, that was previously flooded and inoculated with micro-organism isolates from the over night cultures, these plates were also diluted to $0.1 \mathrm{ml}$, with $10 \mathrm{mls}$ of the nutrient broth and excess culture drained off. The plates were left for 5 minutes on the laboratory bench to allow diffusion of urine and the antibiotic to get ahead of the microbial growth in their respective plates.

The plates were later incubated for 18 hours. The sensitivity patterns of the ocular microbial isolates were determined by measuring in centimeter the zone of inhibition on the plates.

\section{RESULTS}

The microbial isolates from the eye were cultured and identified in their species. These were 
the klebsiella species, Staphylococcus, aureus, pseudomonas species and esherichia coli. The morphology, cultural characteristics, biochemical reaction and fermentation tests suggested the organism that were isolated and cultured (table 1). Table 2 showed three urine samples that were screened and found worthy and fit to be used for sensitivity test, however, their effect on the microbial isolates differ. The urine (U1) from a young adult (28yearss) male showed greater bacteriocidal action to klebsiella species, pseudomonas species and escherichia coli. Urine (U2) came from an elderly man over 65 years and was only found effective on escherichia coli. Urine (U3) was from a 40 year old man and his urine was only sensitive to staphylococcus aureus and pseudomonas species.

\section{DISCUSSION}

The microbial isolates from 50 eye swabs were characterized and identified. The test showed four microorganisms; klebsiella species, staphylococcus aureus. pseudomonas species and escherichia coli. No fungi or virus was isolated.

Table 2 showed the isolates reaction to the urine sample and their zones of inhibition which was measured in centimeters. It was obvious that microbial isolates from infected eyes would not response in the same manner to all urine therapy. The World Health Organisation ${ }^{6}$ gave a minimum standard for sensitivity to chemotherapeutic agents as $0.7 \mathrm{~cm}$. Thus the figures obtain from urine zone of inhibition were very marginal with margin of $0.2 \mathrm{~cm}$ and the minimum of zero.

The mean sensitivity patterns, zone of urine inhibition for all the microbial isolates was 0.63 with $\mathrm{SD} \pm 0.018$. This result fell short of the $\mathrm{WHO}^{6}$ mean standard of $0.7 \mathrm{~cm}$. All the urine sample used did not met the WHO criteria.

For the fact that 50 subjects were selected for this study and only 3 were found free from infection, and other systemic diseases that might affect the normal composition of urine, left much to be desired of the urine as a treatment option for ocular infections. Alternative medicine practitioners claimed that the efficacy of urine therapy has no scientific proofs. Science, on the other hand did not have any scientific proof against limited literatures on these issues, it is possible that urine may be useful in other things or treatment yet to be scientifically discovered, but not in the treatment of ocular diseases; for urine is a toxic waste product from the human body and thus the use of urine is socially unacceptable.

Urine therapy does not have any significant effect on microbial isolates from diseased human eyes. Urine therapy on the eye may further complicate the eye problem because of other disease causing agents it may contain. The difficulties in obtaining healthy urine proved that human urine may not be good enough for any use, and its use at any time is socially unacceptable. Urine did not meet the WHO standard zone of inhibition; the maximum margin over the WHO standard for sensitivity of chemotherapeutic agent is $0.2 \mathrm{~cm}$ and the minimum is zero. The mean for the best quality urine is $0.63 \mathrm{~cm}, \mathrm{SD} \pm 0.018$, and is short by $0.07 \mathrm{~cm}$ from the WHO standard. Therefore, urine should not be considered as treatment option for ocular diseases and the public should be educated and discouraged from such unhealthy practices. Individuals with infected or diseased eyes should seek the advice of trained eye professionals. 
TABLE 1: CHARACTERISATION OF ISOLATES

\begin{tabular}{|c|c|c|c|c|c|}
\hline & $\begin{array}{l}\text { Character I } \\
\text { st I c }\end{array}$ & $\begin{array}{l}\text { K l e b s I e l la } \\
\text { s p e c I e s }\end{array}$ & S. a ur e us & $\begin{array}{l}\text { Pse ud o } \\
\text { mon as }\end{array}$ & E. Col i \\
\hline $\begin{array}{l}\text { Morph } \\
\text { o log } \log \end{array}$ & $\begin{array}{l}\text { Ce l lshapeg } \\
\text { ram Re act I } \\
\text { on med I a U } \\
\text { sed }\end{array}$ & $\begin{array}{l}\text { B a c I l l i } \\
\text { G r a m } \\
\text { N e g a t I ve } \\
(G N B) \\
\text { M c C o n k a y } \\
\text { A g a r (MCA) }\end{array}$ & $\begin{array}{l}\text { Co cci (G P C) } \\
\text { Pos I I I e } \\
\text { Coc c i (ind us } \\
\text { I c r s) } \\
\text { M C A }\end{array}$ & $\begin{array}{l}\text { B a c I l l i } \\
\text { G r a m } \\
\text { N e g a t } \\
\begin{array}{lll}\text { ve } & & \\
M & C & A\end{array}\end{array}$ & 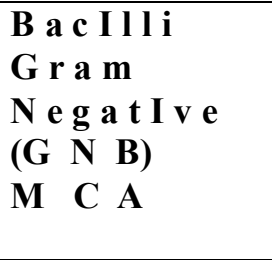 \\
\hline $\begin{array}{l}\text { Cul t } u \\
r \text { a l c h a } \\
r \text { a c t e r } \\
\text { Ist I c s }\end{array}$ & 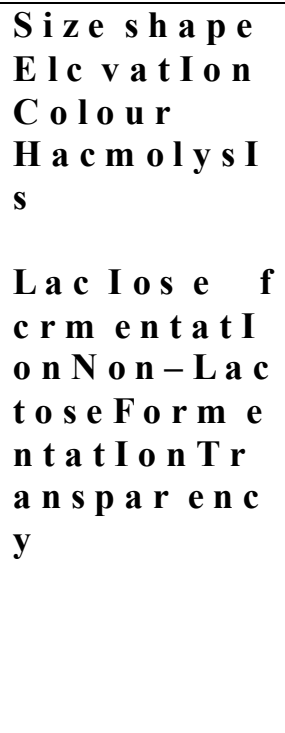 & $\begin{array}{l}0.2-03 \text { m m } \\
\text { Scrrated } \\
\text { Convex } \\
\text { Muco I d } \\
-V c \\
\\
+ \text { ve } \\
- \text { ve } \\
\text { Op a q u }\end{array}$ & $\begin{array}{l}\text { 0.2-0 } 3 \mathrm{~m} \mathrm{~m} \\
\text { Raised } \\
\text { Convex } \\
\text { Pink } \\
\text { Of } \\
\text { Ha e m o l y I s } \\
\text { (c l c a r o n e } \\
\text { Ro u d the } \\
\text { Colon y) } \\
\\
+ \text { v c } \\
\text { - v c } \\
\text { - Tr a n p a r e } \\
\text { nt }\end{array}$ & $\begin{array}{l}0.5-0.6 \mathrm{~m} \\
\text { m } \\
\text { S e r r a t e } \\
\text { d } \\
\text { C r o n v e } \\
\text { x } \\
\text { B r o w n I } \\
\text { s h } \\
\text { No n } \\
\text { H a e m o l } \\
\text { y s I s } \\
\text { (P I g m e n } \\
\text { t) } \\
\text { Pr o d u t } \\
\text { I o n) } \\
\end{array}$ & 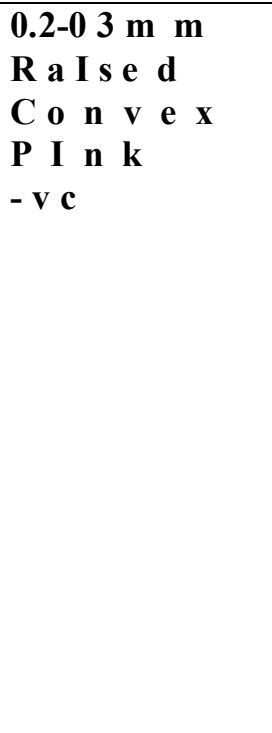 \\
\hline & & & & $\begin{array}{l}+v e \\
-v e \\
\text { O p a q u }\end{array}$ & $\begin{array}{l}+v e \\
-v e \\
\text { Op a q u e }\end{array}$ \\
\hline $\begin{array}{l}\text { B I o c h e } \\
\text { m I c a l R } \\
\text { e a c t I } \\
\text { o n s }\end{array}$ & $\begin{array}{l}\text { Mot I ItyG } \\
\text { ramsReact } \\
\text { IonCatalas } \\
\text { e OxIdase } \\
\text { Coagulase }\end{array}$ & 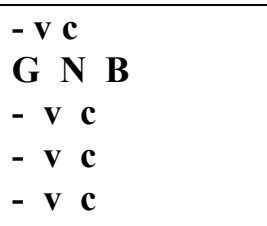 & $\begin{array}{l}-\mathbf{~ c} \\
- \text { G PC } \\
+ \text { ve } \\
-\mathrm{Ve} \\
+\mathrm{ve}\end{array}$ & 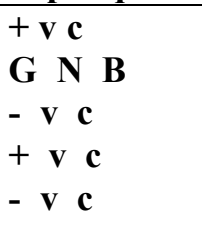 & $\begin{array}{l}+ \text { vc } \\
\text { GN } B \\
-\quad v c \\
+ \text { vc } \\
-\quad v c\end{array}$ \\
\hline $\begin{array}{l}\text { F e r m e } \\
\text { n t a t I o } \\
\text { n T e s t }\end{array}$ & $\begin{array}{l}\text { Indole } \\
\text { Urea } \\
\text { C I t r a t e } \\
\text { G l ucose } \\
\text { Sucrose }\end{array}$ & $\begin{array}{l}+v e \\
-v c \\
A / G=A c ~ I \\
d \\
G \text { a s } \\
\text { / } / G \\
A / G\end{array}$ & $\begin{array}{l}\text { Not } \\
\text { Applica b l e }\end{array}$ & $\begin{array}{lll}- & \mathbf{v} & c \\
- & \mathbf{v} & c \\
- & \mathbf{v} & c \\
- & \mathbf{c} & c \\
- & \mathbf{c} & c\end{array}$ & $\begin{array}{l}+\mathbf{v} \\
-\mathbf{v} \\
\text { A } / \text { G } \\
\text { d } \\
\text { G a s } \mathbf{~ s ~} \\
\text { A/G }\end{array}$ \\
\hline $\begin{array}{l}S \text { u g g } \\
\text { e s t I v e } \\
\text { Org a n } \\
\text { I s m }\end{array}$ & $\begin{array}{l}\text { Suggest Iv } \\
\text { e } \\
\text { Organ I s m }\end{array}$ & $\begin{array}{l}\text { K lebs I c l l a } \\
\text { S p c c I c s }\end{array}$ & $\begin{array}{l}\text { Staph y locec } \\
\text { cus } \\
\text { A ureu }\end{array}$ & $\begin{array}{l}\text { Pscudo } \\
\text { mon a s } S \\
\text { pec I es }\end{array}$ & $\begin{array}{l}\text { Es ch e r I c h } \\
\text { I a } \\
\text { Co li }\end{array}$ \\
\hline
\end{tabular}


TABLE 2: SENSITIVITY PATTERNS ISOLATES TO URINE SAMPLES INCENTIMETERS (ZONES OF INHIBITION)

\begin{tabular}{|l|l|l|l|l|}
\hline $\begin{array}{l}\text { URINE } \\
\text { SAMPLE }\end{array}$ & \multicolumn{3}{|l|}{ MICROBIAL ISOLATE } \\
& $\begin{array}{l}\text { Klebsiella } \\
\text { Species } \mathbf{I}_{\mathbf{1}}\end{array}$ & $\begin{array}{l}\text { Staphylococuss aureus } \\
\mathbf{I}_{\mathbf{2}}\end{array}$ & $\begin{array}{l}\text { Pseudomonas Species } \\
\mathbf{I}_{\mathbf{3}}\end{array}$ & $\begin{array}{l}\text { E. Coli } \\
\mathbf{I}_{\mathbf{4}}\end{array}$ \\
\hline Urine $\left(\mathrm{U}_{1}\right)$ & 0.9 & 0.9 & 0.8 & 0.8 \\
$\operatorname{Urine}\left(\mathrm{U}_{2}\right)$ & 0 & 0 & 0 & 0.9 \\
Urine $\left(\mathrm{U}_{2}\right)$ & 0 & 0 & 0.7 & 0 \\
\hline
\end{tabular}

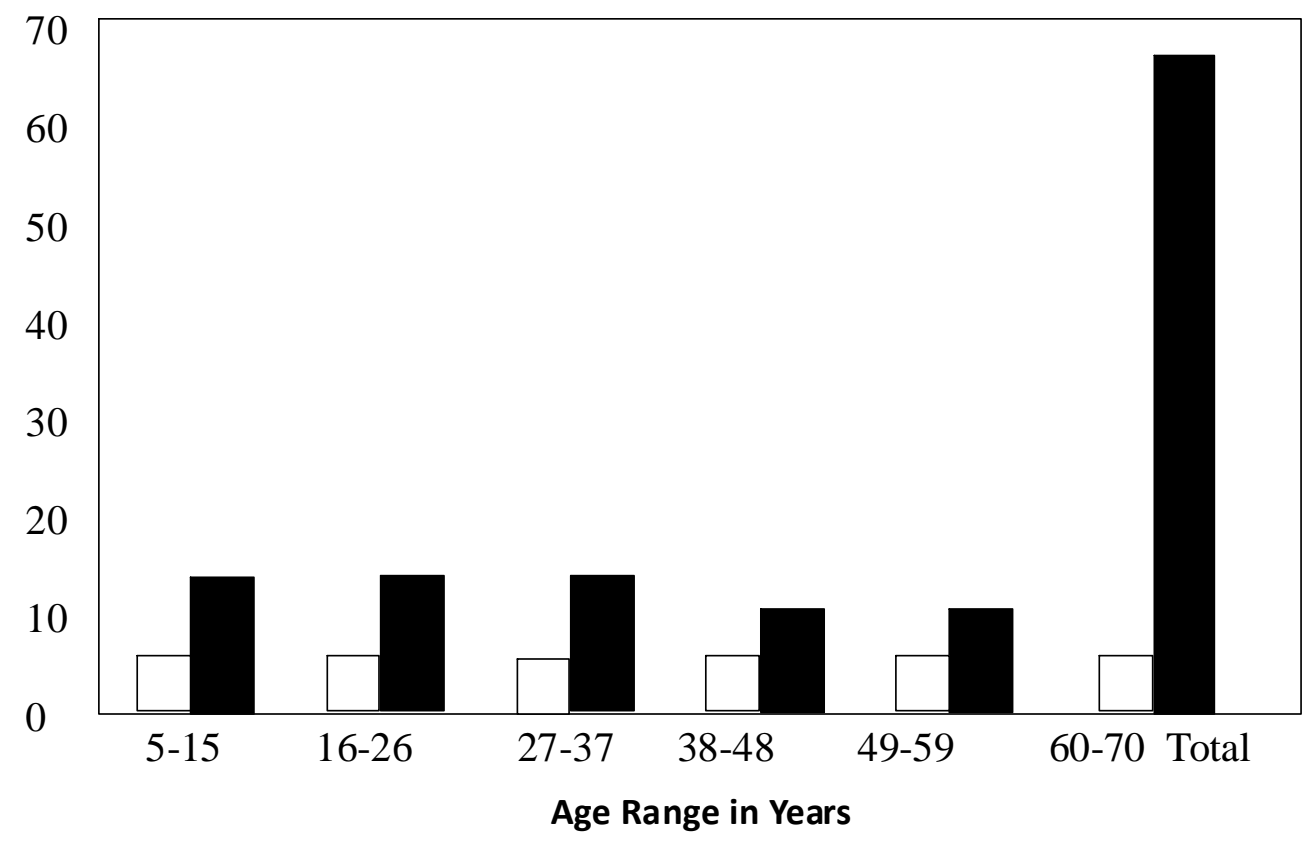

FIG. 1: AGE \& SEX DISTRIBUTION OF TRACHOMA

\section{R E F E R E N C E S}

1. Sanford-Smith, J. (1990): Eye Diseases in Hot Climate. $2^{\text {nd }}$ Edn. Butterworth-Heinemann, England, pp241.

2. Newell, F. W. (1982): Ophthalmology, principles and concept mostly press, London, 559pp.

3. Dart, J. K. C. (1999): Managing Microbial Keratitis Ophthalmologic Society of Nigeria, Quarterly Review July-Sept. 1999.

4. Lewith, G., Kenyon, J. and Lewis, P. (1996): Complementary medicine and integrated approach. Oxford Press, New York.

5. Fulder, S. (1996): Handbook of Alternative and complementary medicine. Oxford Press, London.

a. World Health Organization Strategies for the prevention of Blindness in National programmes. A primary health care approach, 1980.

7. Sharam, U. (1995): Complementary Medicine Today: Practitioners and patient Rout ledge, London.

8. MeGuire, M. (1988): Using Complementary Medicine In: Sharma U Complementary Medicine today: practitioners and patients Rout ledge, London.

9. Heaven, A. (2000): Urine: The foundation of youth. Christian Health Research Keaau, Hawaii.

10. Newberry, P. (2000): Pinkeye- Alternative use of urine. In Marce Murino Marce.

11. Cowan, S. T. and Steel, K. J. (1974): Manual for Identification of medical bacteria.

Cambridge University Press, London, pp2082. 